\title{
Spectator Spending at a Large Regional Volleyball Tournament: An Examination of Survey Methodologies
}

\author{
By Robert Case* \\ Tanujit Dey ${ }^{\dagger}$ \\ Joel Gillespie ${ }^{+}$ \\ Daniel Luckett \\ Maria Pawlosky
}

\begin{abstract}
This study examined the differences between direct spending reported through "in person" surveys administered during a sporting event and online surveys administered after the event. The same direct spending and demographic information questions were used for the "in person" and online surveys. Subjects for the study were spectators to a large multi-day volleyball tournament that was held in the mid-Atlantic region of the United States. Only data from out-of-town respondents was used in this study. Overall, travel party direct spending figures were significantly higher for the "in person" survey respondents than the online respondents.
\end{abstract}

Keywords: Direct spending, survey methodology, online survey, economic impact

\section{Introduction}

The economic impact of sporting events has been extensively studied for a number of years (Baade \& Matheson, 2000; Baade \& Matheson, 2001; Baade, Bauman, \& Matheson, 2008; Crompton \& Lee, 2000). Local communities generally welcome the economic benefits associated with attracting out-oftown visitors to sporting events. According to Kurtzman (2005), hosting a state or regional sport tournament can contribute significantly to the local economy.

In recent years, sport researchers have found that smaller sporting events may have a greater positive economic impact on host communities than large mega sporting events (Agha \& Rashcher, 2012).

Hotels, restaurants, and tourist attractions receive economic benefits when participants, parents, and relatives travel from out-of-town to attend a sporting event. Youth sports, in particular, tend to attract many out-of-town visitors who infuse "new" money into the economy of a host community. An examination of the economic impact associated with sporting events is important for local and regional government officials as the events often rely, in part, on public

\footnotetext{
* Associate Professor, Sport Management Program, Old Dominion University, USA.

${ }^{\dagger}$ Department of Quantitative Health Sciences, Lerner Research Institute, The Cleveland Clinic, USA.

${ }^{+}$The College of William and Mary, USA.

* The College of William and Mary, USA.

The College of William and Mary, USA
} 
funding. For future planning considerations, local government officials like to know if there is a positive return on investment from hosting sporting events (Crompton, Lee, \& Shuster, 2001).

A number of methods have been used over the years to collect direct spending and economic impact data (Eschenfelder \& Li, 2007). In person and telephone interviews, self-administered surveys, on-site self drop-off surveys, mail surveys, expenditure logs, reports or diaries, and the review of post event credit card statements and receipts are some of the methods. In recent years, mobile devices have become more popular in the collection of "real time" survey data.

However, according to Case, Dey, Phang, and Schwanz (2013), two survey methods are still used more often than others to collect event economic impact data. The first survey method is the "in person" paper and pencil survey that is administered at the event. The second type of survey method is the online survey that is often administered after the event has ended. Couper (2000) notes that post event surveys are typically favored, as they are convenient, and usually result in adequate sample sizes which helps to minimize bias. Case and Yang (2009) also report that a high percentage of sport economic impact surveys are still being collected "in person" at sporting events using "mall intercept" and paper/pencil survey methodologies. This is despite the fact that online and mobile device survey methods are becoming affordable and more available.

Economic impact is generally separated into three categories. The first category is total direct spending. Mondello and Rishe (2004) state that "this is the total dollar amount spent at games or events, as well as the amount spent for an entire stay (hotel rooms, food, local vehicle rental,...). Generally speaking, only money originating outside the local economy and spent within the local economy is considered economic impact..." (p. 332).

The second economic impact category includes indirect spending. Indirect spending is the money that recirculates in the local economy as a result of direct spending. This is spending that accrues to businesses that are indirectly impacted by the sporting event through their association with one of the directly impacted businesses. The businesses usually affected by visitors' initial round of spending are hotels, restaurants, and other types of entertainment oriented businesses. The third economic impact category is induced spending. This spending occurs when employers and employees at directly and indirectly impacted businesses receive money from out-of-town visitor spending. For example, employees of a local restaurant that is frequented by visitors to a local golf tournament will eventually spend their income locally to purchase groceries, home supplies,... (Mondello \& Rishe, 2004).

The overall economic impact that a sporting event has on a particular community is further analyzed through the use of multiplier coefficients that aid in determining the total economic impact. Jago and Dwyer (2006) note that Input-Output (I-O) and Computable General Equilibrium (CGE) models are the two main approaches used to estimate the economic impact that an event may have on a host community. Multipliers used to estimate impacts on output, 
income, and employment is invariably based on Input-Output (I-O) models (Crompton, 1999).

\section{Literature Review}

A number of studies (Agha, 2011; de Leeuw, 1992; Dillman, Sangster, Tarnai, \& Rockwood, 1996; Hochstim, 1967; Matheson, 2006; Schuman \& Presser, 1981; Schwartz, Strack, Hippler, \& Bishop, 1991; Seaman, 2004) have analyzed the effects that different survey methodologies have on the quantity and quality of data collection. Dillman and Bowker (2001) and Kehoe and Pitkow (1996), for example, found that using an online survey approach has the potential to increase the number of survey respondents. Hochstim (1967) has stated that survey respondents are more likely to give socially acceptable answers when completing surveys in the presence of an interviewer. Mann and Steward (2000) point out that online survey methods offer a number of advantages when compared to other survey methods as they allow for greater respondent reach by collapsing boundaries of time and space. Moreover, Miller and Hogg (2000) discovered that online survey respondents are likely to respond to sensitive questions more often than telephone survey respondents.

Studies in sport settings that have looked at survey methods tend to focus on direct spending data collected from event participants. For example, in one of the few studies completed in a sport setting that examined differences in survey methods, Olberding and Cobb (2007) reported that online survey approaches are at least as effective as telephone methods when the respondents have some degree of computer literacy. In another study, Case and Yang (2009) studied the differences between in person and online survey methods involving participants of a large marathon event and they found significant differences between the two groups with online respondents reporting higher levels of direct spending. They recommended that the use of online survey methods be considered when conducting direct spending studies for sporting events if respondents have a minimum level of computer literacy. In another study by Case et al. (2013) of participants in a large half-marathon event, it was determined that "in person" during event respondents reported significantly higher direct spending estimates than online respondents. This study was different from previous studies in that this study involved event participants who completed the direct spending surveys "in person" at the event and then online a few days after the event.

Dolnicar, Laesser, and Matus (2009) stated that online survey respondents have a lower dropout rate and produce less incomplete data when compared to traditional paper surveys that are mailed to potential respondents. They noted that survey format can influence the results and that multi-method survey approaches should be used whenever possible. Ward, Clark, Zabriskie, and Morris (2012) found that online respondents tend to feel that their anonymity will be better protected through the use of online survey methods when compared to traditional paper and pencil survey methods. 


\section{Purpose of Study}

Previous studies in sport settings have looked primarily at responses from event participants who completed direct spending surveys either "in person" at the event or online after the event. This study was different in that it attempted to examine direct spending survey results from spectators "in person" at the event and online after the event. Again, the purpose of this study was to examine differences in reported direct spending from spectator respondents who reported travel party direct spending estimates using "in person" during event survey methods and respondents who used online post event survey methods. Therefore, the null hypothesis for this study is that there will be no significant differences in the overall respondent reported travel party average direct spending figures between the "in person" during event and online post event survey methods.

\section{Methodology}

\section{Study Design and Instrumentation}

A sporting event direct spending survey instrument developed by one of the authors was selected for use in this study. The instrument has been used in several sport direct spending and economic impact studies. Selected questions on the survey instrument were modified to fit this particular study. Over the years, a number of experts who conduct direct spending and economic impact studies have reviewed the survey instrument and provided feedback that was used to refine the instrument. The 26-question survey instrument included a variety of questions that were aimed at direct spending and economic impact information. Additional questions on the survey instrument were used to collect demographic information. Eight specific categories of direct spending associated with a volleyball event were measured. The types of questions on the survey instrument ranged from questions about visitor spending on food and beverage to questions about lodging, retail shopping, transportation, tourist attractions, entertainment and recreation, registration and fees...

Groves (1989) points out that the results of surveys can be impacted if precautions are not taken when designing survey research studies. He describes four different sources of survey error. The first source relates to coverage and this occurs when all subjects in a particular sample do not have an equal chance of being selected or included in the group of potential survey respondents. A second source of error is sampling error and this takes place when the characteristics of the sample population are different from the population of interest. The third source of error is measurement error and this occurs when incorrect or inaccurate responses are received due to the poor wording of survey questions, interview bias, incorrect choice of survey method or a problem related to the respondent's behavior. The final source of survey error, according to Groves (1989), relates to non-response error which takes place 
when individuals who did not respond to the survey might have answered survey questions differently than individuals who actually completed the survey.

Subjects for this study were spectators (primarily parents and relatives of participants) who attended a large female dominated volleyball tournament. Over 400 female teams participated in the tournament with volleyball participant age groups ranging from 11 to 18 years. Potential respondents for the "in person" survey were randomly selected and asked to fill out the survey at the tournament. After the tournament, surveys were sent via e-mail to event attendees who were listed on the tournament registration data base. This list included parents and relatives of the tournament volleyball players. Potential respondents were asked not to complete the online survey if they had already completed it at the event.

\section{Data Analysis and Results}

A total of 213 event spectators (e.g., parents and relatives) responded to the "in person" survey that was administered at the event and 88 event spectators responded to the online version of the survey after the conclusion of the event. The average age of the "in person" respondents was 44.3 years and the average age of the online respondents was 45.3 years.

The average party size of the "in person" respondents was 5.3, and the average party size of the online respondents was 4.4. The average round-trip distance traveled to the event by the "in person" respondents was 409 miles, and the average round-trip distance traveled by the online respondents was 431 miles. The "in person" respondents stayed overnight an average of 2.8 nights and the online respondents stayed an average of 2.7 nights. Locals were not included in the data collection or analysis.

Results revealed that $71.3 \%$ of the individuals who responded to the "in person" survey were female and $28.7 \%$ were male (see Figure 1). $57.8 \%$ of the total online respondents were female and $42.2 \%$ were male (see Figure 2). A high percentage of the individuals who responded to the "in person" survey identified themselves as Caucasian $88.4 \%$ and a high percentage of individuals who responded to the online survey $(94.6 \%)$ also identified themselves as Caucasian. African-American respondents comprised the next highest percentage of respondents with $6 \%$ responding to the "in person" survey and $2 \%$ responding to the online survey. 
Figure 1. "In Person" Respondents by Gender (red = male; blue = female)

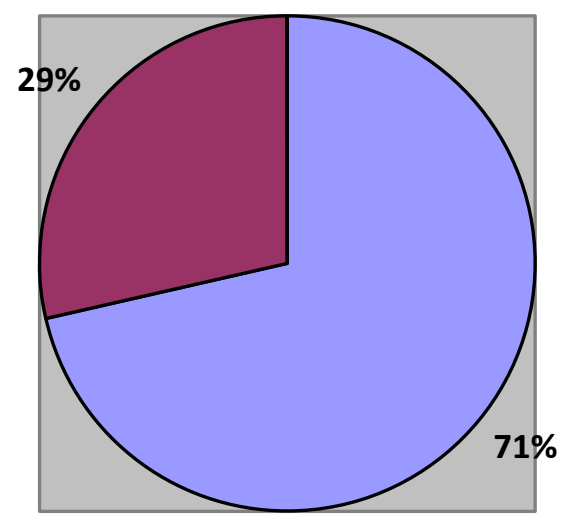

Figure 2. Online Respondents by Gender

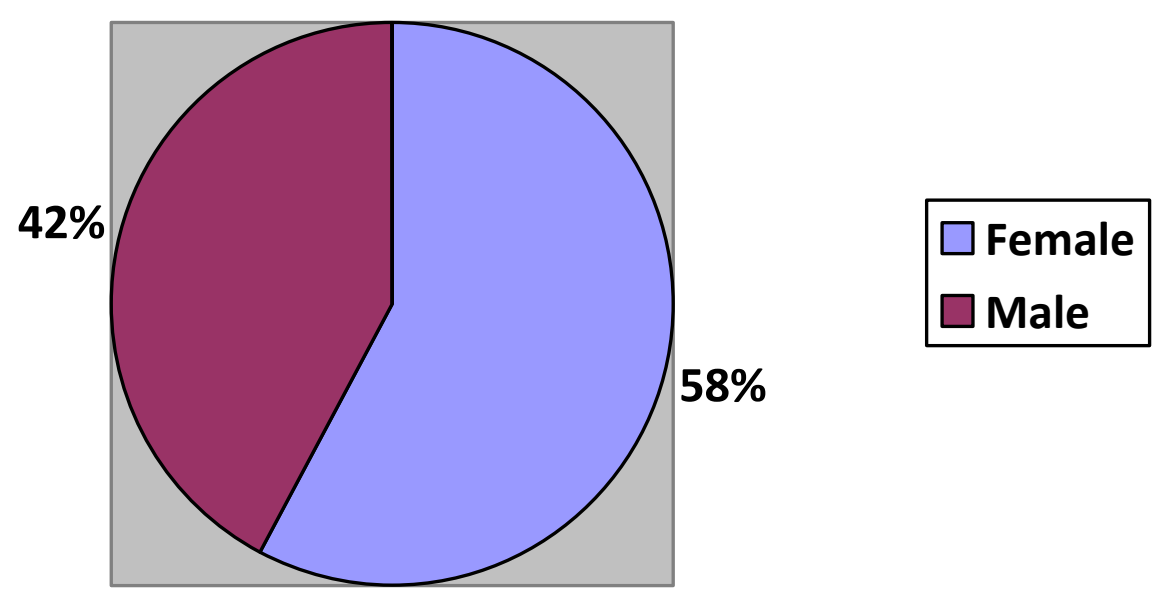

\section{Comparison of Mean Spending for "In Person" and Online Survey Methods}

Mean spending was calculated for the "in person" and online respondents for the direct spending survey questions. The plot below (see Figure 3) indicates that the mean spending for the "in person" group is consistently higher than the mean spending of the online group for each spending category. 
Figure 3. Online versus "In Person" Direct Spending

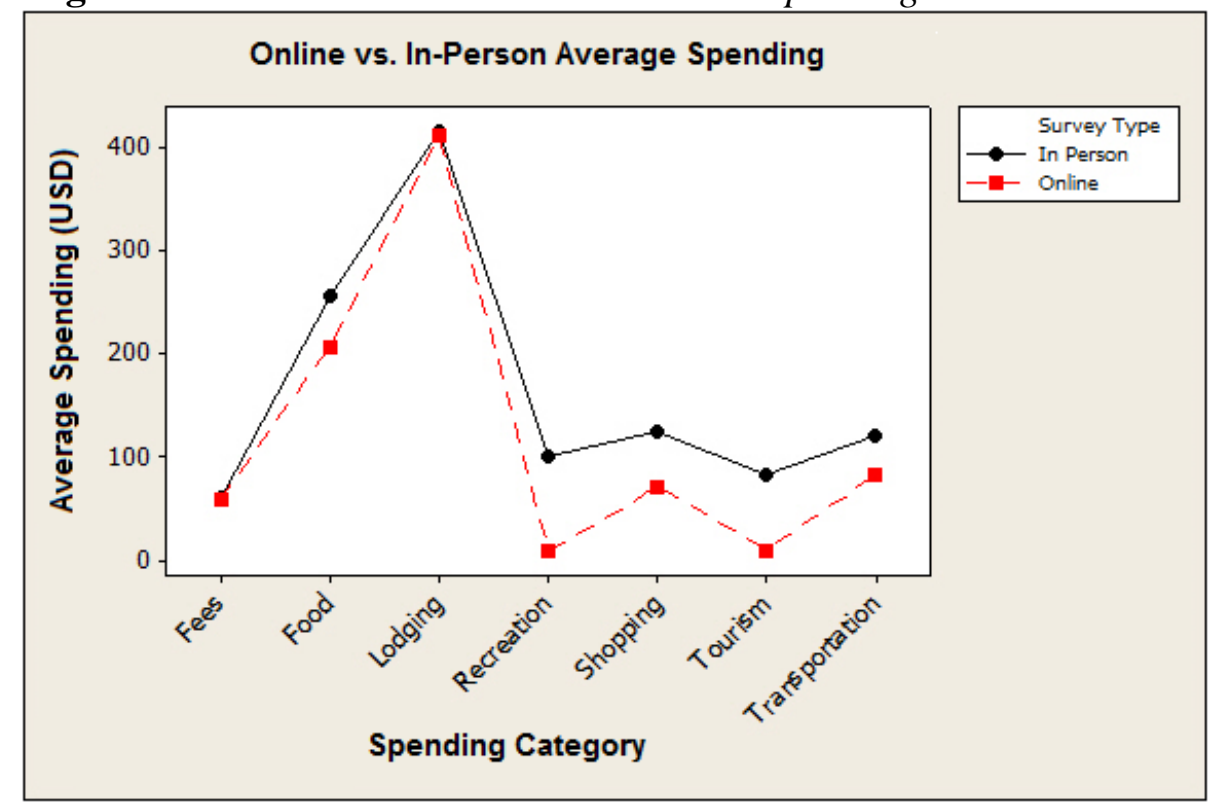

On average, "in person" survey respondents reported spending $\$ 49.20$ more on food and beverage (e.g., restaurants, fast food, convenience stores, groceries,...) than respondents to the online survey. When performing a Student's t-test with level of significance $(\alpha)=.05$ to determine whether the mean spending difference was statistically significant, a p-value of .008 indicated that mean spending was significantly higher for "in person" respondents. A 95\% confidence interval for the difference in spending showed that the true difference in mean spending lies in the range $(\$ 13.1, \$ 85.4)$, where the positive values revealed that spending was higher for "in person" respondents (see Table 1).

Table 1. Summary of spending on Food and Beverage

\begin{tabular}{|l|c|c|c|c|r|c|}
\hline & $\mathbf{N}$ & Min & Max & Mean & Median & St. Dev. \\
\hline Online & 88 & $\$ 13.00$ & $\$ 750$ & $\$ 206.90$ & $\$ 200$ & 144.8 \\
\hline In person & 212 & $\$ 5.23$ & $\$ 800$ & $\$ 256.13$ & $\$ 250$ & 143.1 \\
\hline
\end{tabular}

In addition, respondents to the "in person" survey, on average, reported spending \$3.90 more on lodging (e.g., hotel/motel, condo, camp grounds, time share, cottage,...) than respondents to the online survey. When performing a Student's t-test with $\alpha=.05$ to determine whether the mean spending difference is statistically significant, a p-value of .889 showed that average spending was not significantly higher for "in person" respondents. A 95\% confidence interval for the difference in spending revealed that the true difference in average spending lies in the range $(-\$ 59.4, \$ 51.4)$, where the positive values indicated that spending was higher for "in person" respondents and negative values indicate that spending was higher for online respondents (see Table 2). 
Table 2. Summary of spending on lodging

\begin{tabular}{|l|c|c|c|c|c|c|}
\hline & $\mathbf{N}$ & Min & Max & Mean & Median & St. Dev. \\
\hline Online & 77 & $\$ 0$ & $\$ 1,200$ & $\$ 410.80$ & $\$ 400$ & 221.9 \\
\hline In person & 213 & $\$ 89$ & $\$ 1,000$ & $\$ 414.70$ & $\$ 400$ & 171.9 \\
\hline
\end{tabular}

Spectators responding to the "in person" survey reported spending $\$ 54.30$ more on retail shopping (e.g., clothing, event souvenirs, t-shirts, event merchandise,...) than respondents to the online survey. Further analysis with the Student's t-test with $\alpha=.05$ to determine whether the average spending difference was statistically significant, a $\mathrm{p}$-value $<0.001$ indicated that average spending was significantly higher for "in person" respondents. A 95\% confidence interval for the difference in spending also showed that the true difference in average spending lies in the range $(\$ 27.6, \$ 81.1)$, where the positive values helped determine that spending was higher for "in person" respondents (see Table $3)$.

Table 3. Summary of spending on Retail Shopping

\begin{tabular}{|l|c|c|c|c|c|c|}
\hline & $\mathbf{N}$ & Min & Max & Mean & Median & St. Dev. \\
\hline Online & 78 & $\$ 0$ & $\$ 375$ & $\$ 70.92$ & $\$ 50$ & 71.75 \\
\hline In person & 182 & $\$ 7$ & $\$ 1,700$ & $\$ 125.30$ & $\$ 100$ & 147.1 \\
\hline
\end{tabular}

Spectator respondents to the "in person" survey, on average, reported spending \$37.20 more on transportation (e.g., local rental car, gas, taxi, Uber, parking, tolls, shuttle, ...) than respondents to the online survey. Additional calculations with the Student's t-test with $\alpha=.05$ to determine whether the average spending difference is statistically significant, a p-value $<0.001$ also revealed that average spending was significantly higher for "in person" respondents. A 95\% confidence interval for the difference in spending indicated that the true difference in average spending lies in the range $(\$ 18.61$, $\$ 55.79$ ), where the positive values helped conclude that spending was higher for "in person" respondents (see Table 4).

Table 4. Summary of spending on Transportation

\begin{tabular}{|l|c|c|c|c|c|c|}
\hline & $\mathbf{N}$ & Min & Max & Mean & Median & St. Dev. \\
\hline Online & 85 & $\$ 0$ & $\$ 300$ & $\$ 82.81$ & $\$ 75$ & 58.92 \\
\hline In person & 203 & $\$ 10$ & $\$ 850$ & $\$ 120.01$ & $\$ 100$ & 99.01 \\
\hline
\end{tabular}

On average, respondents to the "in person" survey reported spending $\$ 73.03$ more on tourist attractions (e.g., sightseeing, theme parks, museums, boat rides,...) than respondents to the online survey. When performing a Student's t-test with $\alpha=.05$ to determine whether the average spending difference was statistically significant, a p-value $<0.001$ showed that average spending was significantly higher for "in person" respondents. A 95\% confidence interval for the difference in spending revealed that the true difference in average spending lies in the range $(\$ 53.92, \$ 92.13)$, where the positive values help determine that spending is higher for "in person" respondents (see Table 5). 
Table 5. Summary of spending on Tourist Attractions

\begin{tabular}{|l|c|c|c|c|c|c|}
\hline & $\mathbf{N}$ & Min & Max & Mean & Median & St. Dev. \\
\hline Online & 57 & $\$ 0$ & $\$ 160$ & $\$ 10.07$ & $\$ 0$ & 27.15 \\
\hline In person & 72 & $\$ 10$ & $\$ 500$ & $\$ 83.10$ & $\$ 52.50$ & 75.70 \\
\hline
\end{tabular}

When "in person" respondents answered survey questions about entertainment and recreation spending (e.g., movies, plays, dancing, night life, bowling,...), they reported spending $\$ 92.00$ more on entertainment and recreation than respondents to the online survey. While performing a Student's t-test with $\alpha=.05$ to help determine whether the average spending difference was statistically significant, a p-value $<0.001$ revealed that average spending was significantly higher for the "in person" respondents. A 95\% confidence interval for the difference in spending showed that the true difference in average spending lies between the range ( $\$ 62.00, \$ 122.10)$, where the positive values help conclude that spending is higher for "in person" respondents (see Table 6).

Table 6. Summary of spending on Entertainment and Recreation

\begin{tabular}{|l|c|c|c|c|c|c|}
\hline & $\mathbf{N}$ & Min & Max & & Median & St. Dev. \\
\hline Online & 61 & $\$ 0$ & $\$ 200$ & $\$ 9.57$ & $\$ 0$ & 30.96 \\
\hline In person & 54 & $\$ 0$ & $\$ 500$ & $\$ 101.60$ & $\$ 55$ & 106.5 \\
\hline
\end{tabular}

When looking at "fees" for the event, respondents to the "in person" survey, on average, reported spending $\$ 2.80$ more on registration and fees (e.g., admission to the event) than respondents to the online survey. The Student's t-test with $\alpha=.05$ revealed that the average spending difference was statistically significant. A p-value of .871 showed that average spending was not significantly higher for "in person" respondents. A 95\% confidence interval for the difference in spending also indicated that the true difference in average spending lies in the range ($\$ 37.10, \$ 31.50$ ), with the positive values revealing that spending was higher for in person respondents, and the negative values helped determine that spending was higher for online respondents (see Table 7).

Table 7. Summary of spending on Registration Fees

\begin{tabular}{|l|c|c|c|c|c|c|}
\hline & $\mathbf{N}$ & Min & Max & Mean & Median & St. Dev. \\
\hline Online & 74 & $\$ 0$ & $\$ 750$ & $\$ 58.10$ & $\$ 30$ & 135.3 \\
\hline In person & 156 & $\$ 5$ & $\$ 700$ & $\$ 60.97$ & $\$ 30$ & 89.87 \\
\hline
\end{tabular}

Finally, when looking at total spending for the event, respondents to the "in person" survey, on average, reported spending $\$ 181$ more on direct spending than respondents to the online survey. The Student's t-test with $\alpha=.05$ revealed that the average spending difference was statistically significant. A pvalue of 0.001 showed that average spending was significantly higher for "in person" respondents than the online respondent. A 95\% confidence interval for the difference in total spending also indicated that the true difference in average spending lies in the range $(\$ 71.13, \$ 289.78)$, with the positive values revealing that spending was higher for in person respondents (see Table 8). 
Table 8. Summary of total spending

\begin{tabular}{|l|c|c|c|c|c|c|}
\hline & N & Min & Max & Mean & Median & St. Dev. \\
\hline Online & 88 & $\$ 30$ & $\$ 2375$ & $\$ 771$ & $\$ 713$ & 446.2 \\
\hline In person & 217 & $\$ 140$ & $\$ 2400$ & $\$ 952$ & $\$ 930$ & 416.5 \\
\hline
\end{tabular}

An attempt was made to understand which of the seven dependent variables had the most effect on a respondent's total spending. In order to accomplish this, total spending was calculated for each respondent by summing the respondent's answers for questions 2 through 8 . This sum constitutes the total amount spent by each survey respondent on food and beverage, lodging, retail shopping, transportation, tourist attractions, entertainment and recreation, and registration/fees. The quartiles for the sample of total spending amounts are calculated below (see Table 9).

Table 9. Total spending Amounts for both Categories together

\begin{tabular}{|c|c|c|c|c|c|}
\hline Minimum & $\begin{array}{c}\text { First } \\
\text { Quartile }\end{array}$ & Mean & Median & $\begin{array}{c}\text { Third } \\
\text { Quartile }\end{array}$ & Maximum \\
\hline 30 & 608 & 900 & 871 & 1150 & 2400 \\
\hline
\end{tabular}

Next, the respondents were divided into four groups, where group 1 spent a total amount less than the first quartile, group 2 spent a total amount between the first quartile and the median, group 3 spent a total amount between the median and the third quartile, and group 4 spent a total amount greater than the third quartile. Using the group number as the response and the seven direct spending questions as predictors, a regression model was created. Using Best Subsets Regression, the best model was determined to be the model including all seven predictors. $\mathrm{R}^{2}$ (adjusted) for this model was $82.7 \%$ and Mallow's $\mathrm{C}_{\mathrm{p}}$ was 8.0. The regression equation for this model was as follows: GroupNumber $=0.365+0.00248$ Food +0.00236 Lodging +0.00250 Shopping +0.00219 Transportation +0.00105 Tourist Attractions +0.00329 Entertainment and Recreation +0.00220 Fees.

Table 10. Analysis of Variance Table for this Model yielded the following

\begin{tabular}{|l|l|l|l|}
\hline Predictor & Coefficient & T Value & P-Value \\
\hline Constant & 0.36527 & 5.66 & $<0.001$ \\
\hline Food and beverage & 0.00248 & 11.04 & $<0.001$ \\
\hline Lodging & 0.00236 & 15.62 & 0.889 \\
\hline Retail shopping & 0.00250 & 7.13 & $<0.001$ \\
\hline Transportation & 0.00219 & 6.81 & $<0.001$ \\
\hline Tourist Attractions & 0.00105 & 1.73 & $<0.001$ \\
\hline $\begin{array}{l}\text { Entertainment and } \\
\text { recreation }\end{array}$ & 0.00329 & 6.41 & $<0.001$ \\
\hline Fees & 0.00220 & 7.74 & 0.871 \\
\hline
\end{tabular}

Table 10 (see above) shows that the P-value is very small for every predictor except for lodging and fees. Thus, it can be concluded that the direct spending categories of food and beverage, retail shopping, transportation, tourist 
attractions, and entertainment/recreation are significant when categorizing survey respondents based on total spending.

It is evident from Table 11 (see below) that some variables were influenced by the type of survey taken, and others were not. This, in turn, is most likely a result of the fact that the "in person" surveys were completed before all expenses were incurred and the online surveys had the advantage of being completed after the individual had finished his or her spending. This becomes clear when looking at the individual spending categories. Of the seven spending categories, the expenditures or costs for two of them (lodging and fees) are most likely decided in advance, and therefore the values will not change depending on whether the survey is completed before or after the event visit. The other five (food and beverage, retail shopping, transportation, tourist attractions, and entertainment/recreation) are highly variable, and therefore dependent on what an individual chooses to do during his or her time while attending the sporting event.

Party size, distance traveled, and nights stayed are not spending categories, but they can be analyzed similarly. These three categories, like lodging and fees, are "static," and therefore not likely to change over the course of the event. It is not surprising, then, that there was not a significant difference between the responses from the in person and online respondents. Furthermore, the modeling scheme indicates that respondents did not spend drastically more on some categories than others, in both the in person and online surveys.

It is of note that there was a significant difference in the race and gender of respondents to the online versus in person surveys. Since both samples represent the same population, one would expect the proportions or distributions of race and gender to be comparable for both the "in person" and online samples. Since they are not, this could indicate reasons for differences in the spending data between the two samples. For instance, $71.3 \%$ of the "in person" survey respondents were female compared to $57.8 \%$ of the online respondents being female. Because there was no significant difference between the mean ages of the two samples, age does not appear to be a contributing factor to the difference in the spending data between the two samples.

Although this study was able to determine differences between the two methods of survey data collection (i.e., "in person" during the event and online after the event) and significant differences among selected direct spending variables (e.g., food, retail shopping, transportation, tourist attractions, and recreation), it was limited by an inability to determine which method produces more accurate results. 
Table 11. Overall Summary

\begin{tabular}{|l|c|c|}
\hline & $\begin{array}{c}\text { SIGNIFICANT } \\
\text { DIFFERENCE }\end{array}$ & $\begin{array}{c}\text { NO SIGNIFICANT } \\
\text { DIFFERENCE }\end{array}$ \\
\hline Age & & $\mathrm{X}$ \\
\hline Party Size & & $\mathrm{X}$ \\
\hline Distance Traveled & & $\mathrm{X}$ \\
\hline Nights Stayed & $\mathrm{X}$ & \\
\hline Gender & $\mathrm{X}$ & $\mathrm{X}$ \\
\hline Race & $\mathrm{X}$ & \\
\hline Food & & \\
\hline Lodging & $\mathrm{X}$ & \\
\hline Shopping & $\mathrm{X}$ & $\mathrm{X}$ \\
\hline Transportation & $\mathrm{X}$ & \\
\hline Tourism & $\mathrm{X}$ & \\
\hline Recreation & & \\
\hline Fees & & \\
\hline
\end{tabular}

Since the reported overall spending in the two types of surveys was significantly different (see Table 8), one of the survey methods is clearly more accurate. One can reasonably suspect that the online survey method is the most accurate method because data were collected after the event with less estimating of overall spending. This was an initial and exploratory study involving spectators and not participants. It looked at only the "in person" and online survey groups. Future studies might be designed to examine the following three categories or groups of respondents: (1) a group that is asked to respond to both the "in person" and online surveys; (2) a group that responds to the "in person" survey only; and (3) a group that responds to the online survey only. By using a three group study design and sample, it will be a more "representative" sample and thus allow for a conclusion that can identify the best and most accurate survey method to use. This was a stated limitation of the current study.

\section{Conclusions}

Results of the several comparisons reveal that the null hypothesis established for this study is rejected. As mentioned previously, surveys administered "in person" during the event had significantly higher direct spending averages than surveys administered online after the event. The Student's t-test with $\alpha=.05$ revealed that the average spending difference was statistically significant. A p-value of 0.001 showed that average spending was significantly higher for "in person" respondents than the online respondent. A $95 \%$ confidence interval for the difference in total spending also indicated that the true difference in average spending lies in the range (\$71.13, \$289.78), with the positive values revealing that spending was higher for "in person" respondents (see Table 8).

It was recommended that in the future studies be conducted that compare other survey methodologies such as event journals, event diaries, and financial 
log methods of data collection with the "in person" and online survey methods used in this study. It has been reported (Breen, Bull, \& Walo, 2001; Faulkner \& Raybould, 1995) that journal and diary methods are highly accurate so using them for a comparison with "in person" during event and post event online survey methods is suggested. With the increased usage and expanded capability of mobile devices such as iPhones and iPads, it is very likely that within the next five years new technologies will make the collection of instant "real time" data and spending patterns a reality with point of purchase chips and internet cloud postings being used more frequently. Several commercially available online survey programs are available (e.g., Survey Monkey, SurveyGizmo) where spectators can open the program remotely from their mobile devices to answer survey questions at any time during or after the event. The response data is then instantly uploaded to a "cloud based site" via the internet.

In addition, more research needs to be conducted on differences between participant and spectator spending patterns at events. Spectators attending sporting events like volleyball generally have more time to look at and spend money on merchandise, souvenirs, and concessions than individuals actually participating or competing in the sporting event. As a result, when completing "in person" and online direct spending surveys, differences may exist. Spending differences by race, age, gender, and income levels are other variables that should continue to be explored.

As recommended in other studies (Dolnicar, Laesser, \& Matus, 2009; Case $\&$ Yang, 2009), perhaps the best future approach to conducting sport economic impact studies may be to tailor the survey methods to fit the specific study situation. In other words, some studies may call for "in person" during event paper and pencil survey methods, some studies may call for post event online survey methods, some studies and events have information pertaining to registered participants and event attendees (e.g., spectators) and other events do not. Some direct spending studies may call for keeping financial journals or diaries, others may require the use of high tech mobile devices, additional studies may require the use of a pre-paid debit card or some other type of identification method to track sporting event purchasing and other spending habits. Finally, selected studies may call for the use of multiple data collection methods. It does appear that the combination of technology and the use of mobile devices will change the face of sporting event direct spending survey methods with traditional paper and pencil methods eventually becoming obsolete.

\section{References}

Agha, N. (2011). The economic impact of stadiums and teams: The case of minor league baseball. Journal of Sports Economics, 12(5), 1-26.

Agha, N., \& Rascher, D. (2012). When can economic impact be positive? Twelve conditions that explain why smaller sports have bigger impacts. Presentation at the North American Society for Sport Management, Seattle, WA.

Baade, R., \& Matheson, V. (2000). High octane? Grading the economic impact of the Daytona 500. Marquette Sports Law Journal, 10, 401-415. 
Baade, R., and Matheson, V. (2001). Home run or wild pitch? Assessing the economic impact of major league baseball's All-Star Game. Journal of Sport Economics, 2(4), 307-327.

Baade, R, Bauman, R., \& Matheson, V. (2008). Assessing the economic impact of college football games on local economies. Journal of Sport Economics, 20(10), 1-16.

Breen, H., Bull, A., \& Walo, M. (2001). A comparison of survey methods to estimate visitor expenditure at a local event. Tourism Management, 22(5), 473-479.

Case, R., Dey, T., Lu, J., Phang, J., \& Schwanz, A. (2013). Participant spending at sporting events: An examination of survey methodologies, Journal of Convention and Event Tourism, 14 (1), 21-41.

Case, R., \& Yang, W. (2009). A study to examine differences between in person and online survey data collection methodologies. Sport Management International Journal, 5(2), 6-20.

Couper, M. (2000). Web surveys: A review of issues and approaches. Public Opinion Quarterly, 64, 464-494.

Crompton, J. (1999). Measuring the economic impact of visitors to sports tournaments and special events. National Recreation and Park Association, Division of Professional Services, Ashburn, VA.

Crompton, J., Lee, S.. \& Schuster, T. (2001). A guide for undertaking economic impact studies: The Springfest example. Journal of Travel Research, 40, 79-87.

Crompton, J. \& Lee, S. (2000). The economic impact of 30 sports tournaments, festivals, and spectator events in seven U.S. cities. Journal of Park and Recreation Administration, 18, 107-126.

DeLeeuw, E. (1992). Data quality in mail, telephone and face-to-face surveys. Amsterdam: TT Publications.

Delpy, L., \& Li, M. (1998). The art and science of conducting economic impact studies. Journal of Vacation Marketing, 4, 230-254.

Dillman, D.A., Sangster, R.L., Tarnai, J., \& Rockwood, T. (1996). Understanding differences in people's answers to telephone and mail surveys. In M.T. Braverman \& J.K. Slater (Eds.), Advances in survey research. San Francisco: Jossey-Bass.

Dillman, D.A., \& Bowker, D.K. (2001). The web questionnaire challenge to survey methodologists. In U.D. Reips \& M. Bosnjak (Eds,), Dimensions of internet science. Lengerich, Germany: Pabst Science Publishers.

Dolnicar, S., Laesser, C., \& Matus, K. (2009). Online versus paper: Format effects in tourism surveys Journal of Travel Research, 47(3), 295-316.

Eschenfelder, M.J., \& Li, M. (2007). Economics of sport. Morgantown, WV: FIT.

Faulkner, B., \& Raybould, M. (1995). Monitoring visitor expernditure associated with attendance at sporting events: An experimental assessment of the diary and recall Methods. Festival Management and Event Tourism, 3(2), 73-81.

Groves, R.M. (1989). Survey errors and survey costs. New York: Wiley.

Hochstim, J.R. (1967). A critical comparison of three strategies for collecting data from households. Journal of the American Statistical Association, 62, 976-989.

Jago, L., \& Dwyer, L (2006). Economic evaluation of special events: A practitioner's guide. Victoria, Australia: Common Ground Publishing.

Kehoe, C., \& Pitkow, J. (1996). Surveying the territory: GVU's five WWW user surveys. The World Wide Web Journal, 1.

Kurtzman, J. (2005). Economic impact: Sport tourism and the city. Journal of Sport Tourism, 10(1), 47-71.

Mann, C., \& Steward, F. (2000). Internet communication and qualitative research: A handbook for researching online. Thousand Oaks, CA: Sage Publications. 
Matheson, V. (2006). Mega-Events: The effect of the world's biggest sporting events local, regional, and national economies. College of Holy Cross Department of Economics.

Mid-East Qualifier. (2010, December). Lids team sport mid-east qualifier. Retrieved December 1, 2010, from http://www.meqexpo.com/

Miller, J., \& Hogg, A. (2000). Internet vs. telephone data collection: Does method matter? Burke White Paper Series, 2(4). Retrieved March 2, 2009, from www.burke.com.

Mondello, M., \& Rishe, P. (2004). Comparative economic impact analyses: Differences across cities, events, and demographics. Economic Development Quarterly, 18(4), 331-342.

Olberding, D., \& Cobb, S. (2007). Online and telephone surveys: The impact of survey mode on spending estimates by participants in a major urban marathon. CHPERSD Journal of Research, 2(1), 27-32.

Papanikos, G. (2015). The economic effects of a marathon as a sport tourism event. Athens Journal of Sports, $X(Y), 1-15$.

Sax, L., Gilmartin, S., \& Bryant, A. (2003). Assessing response rates and non-response bias in web and paper surveys. Research in Higher Education, 44(4), 409-432.

Schuman, H., \& Presser, S. (1981). Questions and answers in attitude surveys: Experiments on question form, wording and context. New York: Academic Press.

Schwartz, N., Strack, L, Hippler, H., \& Bishop, G. (1991). The impact of administration mode of response effects in survey measurement. Applied Cognitive Psychology, $5,139-212$.

Seaman, B. (2004). The supply constraint problem in economic impact analysis: An arts/sports disparity. Lasting Effects: Assessing the Future of Economic Impact Analysis of the Arts Conference, Tarrytown, NY.

Soderberg M (2014) Willingness to pay for nontraditional attributes among participants of a long-distance running race. Journal of Sports Economics 15(3): 285-302.

Taks M, Kesenne S, Chalip L, Green CB (2011) Economic impact analysis versus cost benefit analysis: The case of a medium-sized sport event. International Journal of Sport Finance 6(3): 187-203.

Ward, P., Clark, T., Zabriskie, R., \& Morris, T. (2012). Paper/pencil versus online data collection: An exploratory study. Journal of Leisure Research.44(4), 507-530.

Wicker P, Hallmann K, Zhang JJ (2012) What is influencing consumer expenditure and intention to revisit? An investigation of marathon events. Journal of Sport \& Tourism 17(3): 165-182. 
